\title{
Monitoring of Grinding Status of Alumina Grinding Wheel Based on Short-time Fourier Transform
}

\author{
Kun-Ying Li, ${ }^{1}$ Yue-Feng Lin, ${ }^{2}$ Ming-Yi Tsai, ${ }^{2 *}$ \\ I-Cheng Chiu, ${ }^{2}$ and Jyun-Yan Chen ${ }^{1}$
${ }^{1}$ Graduate Institute of Precision Manufacturing, National Chin-Yi University of Technology, No. 57, Sec. 2, Zhongshan Rd., Taiping Dist., Taichung 41170, Taiwan
${ }^{2}$ Department of Mechanical Engineering, National Chin-Yi University of Technology, No. 57, Sec. 2, Zhongshan Rd., Taiping Dist., Taichung 41170, Taiwan

(Received May 11, 2021; accepted September 14, 2021)

Keywords: aluminum oxide grinding wheel, accelerometer, short-time Fourier transform

In this study, an accelerometer was installed on a computer numerical control (CNC) grinding machine, and the vibration signal of the accelerometer was processed by short-time Fourier transform (STFT) to observe the correlation between the wear behavior of the grinding wheel and the characteristic frequency during the grinding process. Two sets of accelerometers were adopted to collect the vibration signal, which was transformed to a time-frequency diagram by STFT. From the time-frequency diagram, it was deduced that the frequency bands of the grinding wheel and the workpiece were $500-700 \mathrm{~Hz}$ and $1200-1280 \mathrm{~Hz}$, respectively. According to the comparison between the frequency band and the time-frequency diagram of the sensing signal at the workpiece with surface roughnesses $R_{a}$ and $R_{Z}$, when the spectral energy increased, the surface roughness of the workpiece increased significantly, the self-sharpening was completed at the same time, and the increased surface roughness of the workpiece was maintained.

\section{Introduction}

In recent years, due to the rapid development of science and technology, the requirements for high-precision components and molds have gradually increased. Therefore, it has become even more important to develop key technologies for precision manufacturing and grinding tools. In general, grinding wheels for grinding machines require high rigidity, durability, crack resistance, a good damping ratio, and thermal conductivity in industrial applications. In addition, grinding wheels must be applicable to both traditional finishing applications and high-performance grinding. ${ }^{(1-4)}$

The rapid development of grinding tools has also led to the development and application of high-performance grinding machines and superhard abrasive grinding wheels. ${ }^{(5)}$ However, the edges and corners of grinding wheels are gradually rounded during grinding, which reduces the self-sharpening ability of grinding wheels. ${ }^{(6)}$ As a result, in addition to a reduced grinding force

*Corresponding author: e-mail: mytsai@ncut.edu.tw https://doi.org/10.18494/SAM.2021.3578 
and poor surface roughness, the pores on the surface of grinding wheels become filled with debris as a result of grinding, causing the grinding wheel to become a serrated plane and lose its grinding force.

As the grinding force of the grinding wheel gradually deteriorates, the grinding wheel must be pruned to restore its grinding force. However, the high rotational speed of the grinding wheel during the grinding process makes it impossible to directly observe the variation in its grinding force. Should the grinding force of the grinding wheel deteriorate, abnormal grinding phenomena will occur, indicating that pruning is necessary. ${ }^{(7-9)}$

To enhance the use time and grinding accuracy of grinding wheels, $\mathrm{Wu}$ et al. ${ }^{(10)}$ and Srivastava et al. ${ }^{(11)}$ utilized a high-speed grinding machine to investigate the effects of the grinding force, temperature, and surface characteristics on the surface accuracy of the workpiece in the grinding of $\mathrm{SiC}$ materials. They compared the relationship between the real-time grinding force, temperature, and visual appearance of damage and debris in SEM micrographs. They found that the ductile mode grinding of $\mathrm{SiC}$ can be achieved by increasing the wheel speed and controlling the grinding parameters. Dai et al. ${ }^{(12)}$ investigated the influence of the rotational speed of a vitrified cubic boron nitride grinding wheel on the grinding temperature and power consumption in the grinding of Inconel 718 nickel-based superalloy. They found that the grinding load of a single grain of vitrified cubic boron nitride abrasive is an important parameter that directly affects the surface accuracy, and the relationship with the surface roughness can also be evaluated from the grinding load of a single grain of vitrified cubic boron nitride abrasive. In experiments, they found that the rotational speed of the grinding wheel could be increased to $100-120 \mathrm{~m} / \mathrm{s}$ when grinding Inconel 718 and they achieved a surface roughness $R_{a}$ of less than $0.4 \mu \mathrm{m}$.

Recently, the application of AI in machine tool automation has rapidly progressed. Rowe et al. ${ }^{(13)}$ proposed AI algorithms to enhance the surface accuracy after grinding and improve the efficiency of the grinding process. Maksoud et al. ${ }^{(14)}$ proposed the use of the backpropagation (BP) learning algorithm in an artificial neural network (ANN) to operate a grinding controller. The method was adopted to monitor signals of the grinding wheel speed and feed rate and adjust control strategies to satisfy the required surface roughness accuracy. Yang and $\mathrm{Yu}^{(15)}$ adopted discrete wavelet transform and support vector machine methods to establish a wear monitoring system for grinding wheels. The monitoring system utilized an acoustic emission (AE) sensor to collect the grinding signal so as to identify the preprocessing method of the grinding cycle signal, and they conducted various grinding experiments on a surface grinding machine, achieving a prediction accuracy of the monitoring system of $99.39 \%$. Also, Arriandiaga and coworkers ${ }^{(16,17)}$ adopted ANNs to establish virtual sensors for random and nonlinear grinding processes that can instantly monitor grinding factors and power changes in the spindle. By comparing the signal of a virtual sensor with the actual measurement result in an industrial grinding machine, the wear condition of the grinding wheel and the surface roughness grinding performance were effectively predicted. Arriandiaga et al. ${ }^{(18)}$ adopted a recurrent neural network algorithm to predict the wear of a grinding wheel and the surface roughness. They found that grinding conditions have a greater influence on surface roughness prediction than the characteristics of the grinding wheel. Past studies ${ }^{(13-18)}$ have pointed out that the data 
collected by the built-in sensors of a machine can be used to perform AI algorithm calculations to predict grinding wheel wear. For instance, Han and $\mathrm{Wu}^{(19)}$ utilized an AE sensor to monitor grinding surface characteristics and investigated the relationship between them and the AE waveform under different grinding conditions. They found that there is a clear mapping relationship between the grinding parameters and the AE signal. There is a high correlation between the AE root mean square (RMS) and the linear velocity of the grinding wheel. Also, Lopes et al. ${ }^{(20)}$ proposed a new AE signal grinding method to identify the correct pruning time. The AE signal was collected in a pruning test carried out using an alumina grinding wheel and a single-point pruner. The power spectrum density was subjected to spectral analysis to find the characteristic relationship between the grinding parameters and the surface. The result can be used to determine the status of the grinding wheel and thus monitor the grinding wheel. In another study, Wang et al. ${ }^{(21)}$ proposed an ANN method to detect the burn surface characteristic of a workpiece (the undesirable changes in the metallurgical properties of the material caused by excessive corrosion or inappropriate grinding). The AE signal was used to analyze the hardness and contour results (burning or nonburning) after grinding using the feature vector of an ANN. Martins and Aguiar ${ }^{(22)}$ established an ANN model to judge the correlation between the AE signal and grinding wheel wear. A statistical technique was used to analyze the power of frequency bands selected from the AE spectrum, and the signal characteristics were obtained to evaluate the frequency bands as the input of the neural network model. It was found that the wear condition of the grinding wheel appeared in the $28-33$ and $42-50 \mathrm{kHz}$ frequency bands.

In this study, an accelerometer was installed on a computer numerical control (CNC) grinding machine, and the vibration signal of the accelerometer was processed by short-time Fourier transform (STFT) to observe the correlation between the wear behavior of the grinding wheel and the characteristic frequency during the grinding process. Two sets of accelerometers were adopted to collect the vibration signal, which was transformed to a time-frequency diagram by STFT. By using the time-frequency diagram to deduce the frequency bands of the grinding wheel and the workpiece, the beginning and the end of the self-sharpening phenomena could be clearly observed, and it was found that the energy generated when the second self-sharpening phenomenon occurred was significantly higher than that for the first phenomenon. It was presumed that the self-sharpening phenomena could not perfectly repair the grinding wheel to its best state and that insufficient grinding ability caused the energy to surge.

\section{Experimental Equipment and Setup}

\subsection{Experimental equipment}

An ESG-1020CNC (EQUIPTOP Technology, Taiwan) grinding machine was used in this study. The workbench dimensions of the grinding machine were $300 \times 650 \mathrm{~mm}$ and the maximum feed rate was $18 \mathrm{~m} / \mathrm{min}$. The maximum rotational speed of the spindle was $12000 \mathrm{rpm}$ $(>100 \mathrm{~m} / \mathrm{s})$ and the positioning accuracy was $0.001 \mathrm{~mm}$. A three-axis accelerometer and the NI capture card of the signal sensing instrument were installed in the grinding machine. The measuring equipment is shown in Fig. 1. 


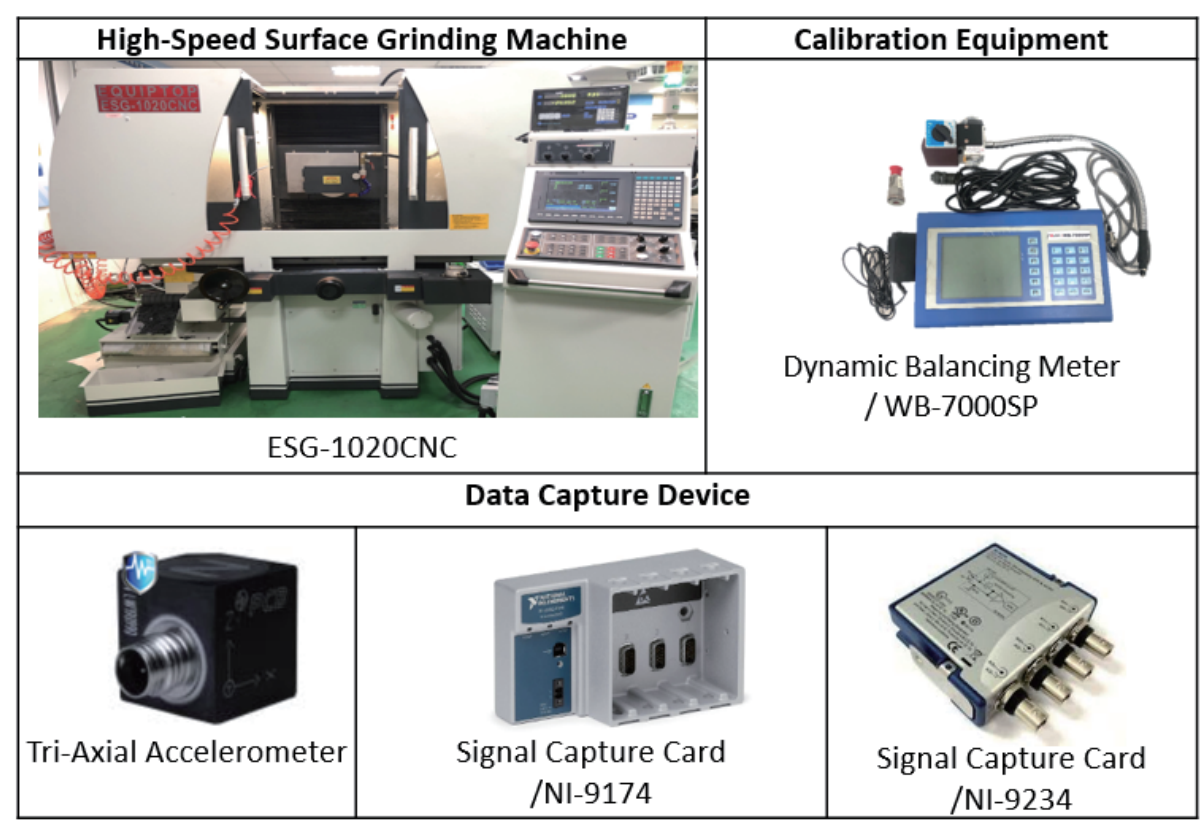

Fig. 1. (Color online) High-speed surface grinding machine.

Table 1

(Color online) Material specifications of grinding wheel and workpiece.

\begin{tabular}{cc}
\hline Grinding Wheel and Workpiece & Specifications \\
\hline $\begin{array}{l}\text { Aluminum oxide } \\
\text { grinding wheel }\end{array}$ & Granularity $\times \mathrm{H} \times \mathrm{V}=205 \times 13 \times 31.75$ \\
S45C & C: $0.42-0.48 ;$ Si: $0.15-0.35 ;$ \\
Mn: $0.60-0.90 ;$ \\
S: $\leq 0.035 ; \mathrm{P}: \leq 0.030$
\end{tabular}

An aluminum oxide grinding wheel (KINIK) was used in this study. The workpiece material was S45C steel with the standard JIS and ISO specifications. The grinding wheel and material characteristics are shown in Table 1.

\subsection{Setup of experimental equipment}

In the experiment, the vibration signal measured by accelerometers was used to investigate the grinding characteristics and wear mechanism of the grinding wheel for $\mathrm{S} 45 \mathrm{C}$ steel processing. The accelerometers were placed on the spindle guard and the workbench to measure the vibration signal of the grinding wheel, and the vibration signal of the accelerometer was transformed to a time-frequency diagram by STFT. Figure 2 shows the placement of the accelerometers. 


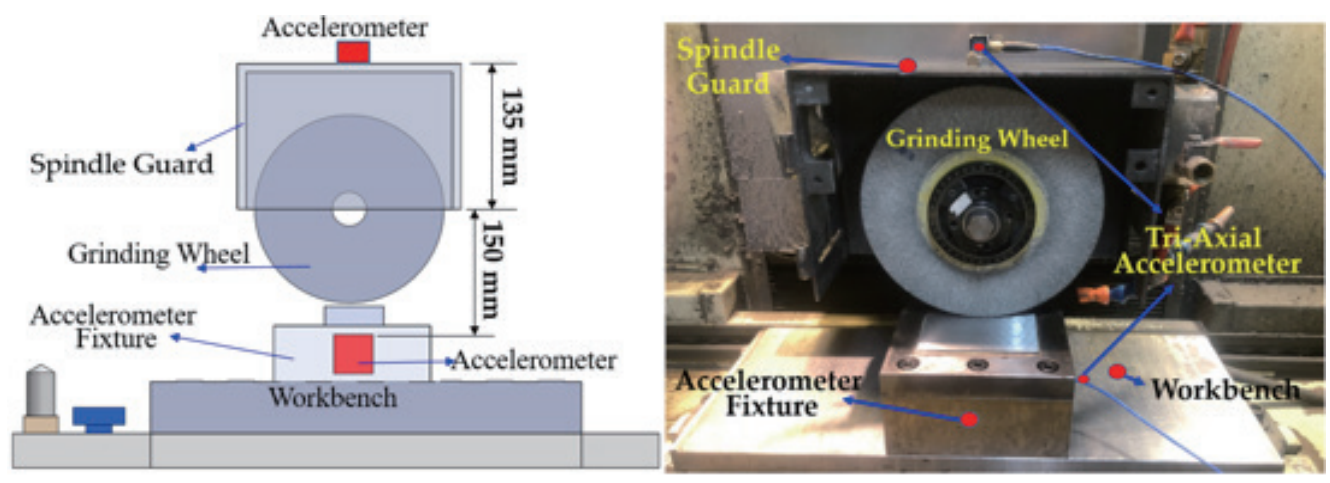

Fig. 2. (Color online) Accelerometer placement.
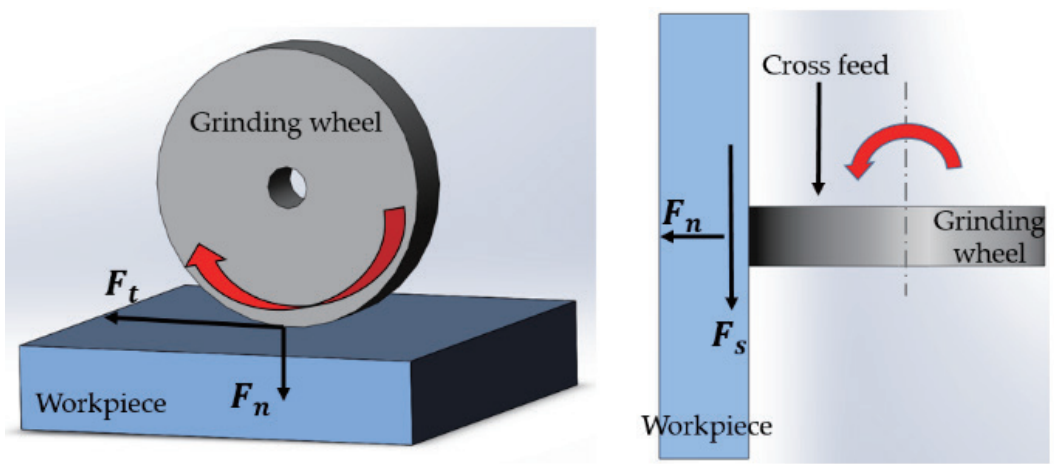

Fig. 3. (Color online) Grinding forces in grinding process.

\subsection{Theoretical analysis of grinding and STFT}

As a workpiece is ground by the grinding wheel of a grinding machine, the grinding wheel is subjected to a grinding resistance. This resistance can be divided into the radial grinding force $\left(F_{n}\right)$, tangential grinding force $\left(F_{t}\right)$, and lateral feed grinding force $\left(F_{s}\right)$, as shown in Fig. 3.

In the grinding process, the radial grinding force is the largest and more than twice the tangential grinding force. The horizontal feed grinding force is extremely small and can usually be ignored. Equations (1) and (2) give the grinding force $\left(F_{n}\right)$ and grinding power $\left(P_{m}\right)$, where $C_{F}$, $C_{P}$, and $K$ are empirical coefficients and $B$ is the width of the grinding wheel. Equation (3) is used to calculate the material removal rate of the grinding wheel width $\left(Z_{s}\right)$, where $V_{w}$ is the workpiece feed rate, $f_{a}$ is the lateral feed, and $f_{r}$ is the radial feed.

$$
\begin{gathered}
F_{n}=C_{F} \times Z_{s}^{0.7} \times B \times K \\
P_{m}=\frac{C_{p}}{1000} \times Z_{s}^{0.7} \times B \times K \\
Z_{s}=\frac{1000 V_{w} \times f_{r} \times f_{a}}{B}
\end{gathered}
$$


The thermal damage of precision parts makes them unable to meet the requirements of dimensional precision. The thermal damage of high-precision parts (such as thermal cracks, burns, tempering softening of materials, and residual stress) is caused by the high processing temperature during grinding. The grinding effect is caused by the high-speed grinding of the workpiece with the negative bevel abrasive grain cutting edge; the heat generated by grinding is transmitted to the workpiece and the grinding wheel. The heat is taken away by the grinding fluid and grinding chips. The grinding temperature can reach $1000{ }^{\circ} \mathrm{C}$, which is the average temperature of the contact between the grinding wheel and the workpiece. Figures 4(a) and 4(b) show the grinding point temperature of the grinding wheel and the grinding point temperature of the abrasive particles, respectively.

The calorific value between the grinding wheel and the grinding point of the abrasive grain can be calculated by Eqs. (4) and (5).

$$
Q=q_{0} \times B \times l_{c}
$$

Here, $Q$ is the calorific value per unit time, $B$ is the width of the grinding wheel, $l_{c}$ is the contact arc length, and $q_{0}$ is the calorific value divided by the unit area and unit of time.

$$
Q=\frac{f_{t} V_{s}}{J}
$$

Here, $f$ is the tangent grinding force of a single particle, $V_{S}$ is the grinding speed, and $J$ is the thermal equivalent of the grinding process.

\subsection{Theoretical analysis of continuous STFT}

In this study, an accelerometer was used to measure the vibration signal during the grinding of the grinding wheel, and the vibration signal was transformed by STFT to observe the

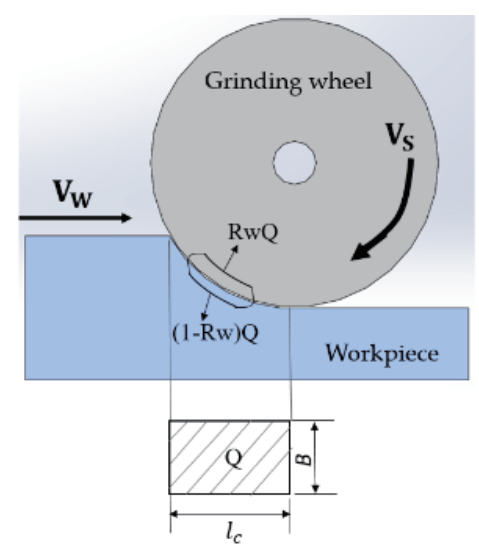

(a)

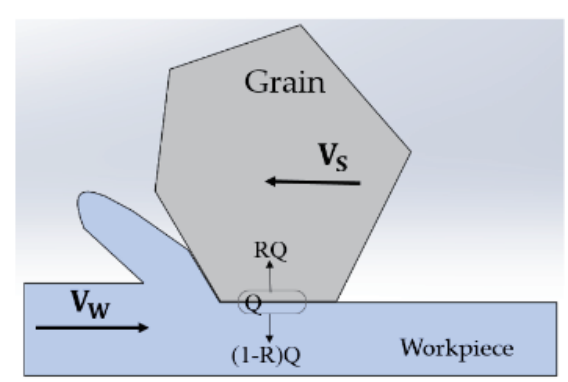

(b)

Fig. 4. (Color online) Grinding point temperatures: (a) grinding wheel and (b) abrasive grain. 
correlation between the wear behavior and the characteristic frequency of the grinding wheel during the grinding process. The mathematical definition of $\operatorname{STFT}^{(23)}$ is

$$
X(t, f)=\int_{-\infty}^{\infty} \omega(t-\tau) x(\tau) e^{-j 2 \pi f_{\tau}} d \tau
$$

where $\omega(t)$ is the window function, $x(t)$ is the signal to be transformed, and $X(t, \omega)$ is the Fourier transform of $\omega(t-\tau) x(\tau)$. As $t$ changes, the window function shifts on the timeline. After calculating the function $\omega(t-\tau) x(\tau)$, the signal only leaves the intercepted part of the window function for the final Fourier transform. The result is a complex function, which represents the magnitude and phase with the time and frequency of the signals.

\section{Results and Discussion}

To observe the self-sharpening phenomena (abrasive fracture, chip adhesion, shedding, and wear) and related characteristics of the grinding wheel during the grinding process, we designed a set of continuous grinding experiments. The duration of each single grinding in an experiment was 30 min with no dressing of the grinding wheel during the process, and the experiment was continued until significant abnormalities and characteristics appeared on the grinding wheel and workpiece and in the vibration signal. Experiments were divided into two groups with an accelerometer installed on the spindle guard of the grinding wheel or the workpiece fixture.

By installing an accelerometer at different positions in the experiment, we were able to analyze the vibration signals separately. The characteristic frequency bands of the grinding wheel and the workpiece were distinguished by the frequency band characteristics, and the correlations between the grinding wheel and the workpiece with grinding chatter and other phenomena were observed. The single-feed depth was set to $10 \mu \mathrm{m}$ for grinding, with a feed pitch of $2 \mathrm{~mm}$, spindle speed of $2000 \mathrm{rpm}$, table feed speed of $15 \mathrm{~m} / \mathrm{min}$, and $500 \mu \mathrm{m}$ total depth of grinding. The grinding conditions are shown in Table 2 . The total grinding time was $360 \mathrm{~min}$.

\subsection{Characteristic frequency band of grinding wheel and workpiece}

We performed STFT on the sampled data obtained by the accelerometers in the two sets of experiments and observed the changes in the frequency band energy generated by the grinding wheel and the fixture over time, as shown in Figs. 5(a)-5(d). From the results, the main spectrum

Table 2

Grinding conditions.

\begin{tabular}{lclc}
\hline Item & Condition & Item & Condition \\
\hline Material & S $45 \mathrm{C}$ & Speed of workpiece & $15 \mathrm{~m} / \mathrm{min}$ \\
Wheel type & WA-60 & Workpiece stroke & $200 \mathrm{~mm}$ \\
Total removal & $500 \mu \mathrm{m}$ & Roughing & $10 \mu \mathrm{m}$ \\
Wheel speed & $21.5 \mathrm{~m} / \mathrm{s}$ & Cutting pitch & $2 \mu \mathrm{m}$ \\
Rotating speed & $2000 \mathrm{rpm}$ & Time & $30 \mathrm{~min}$ \\
\hline
\end{tabular}




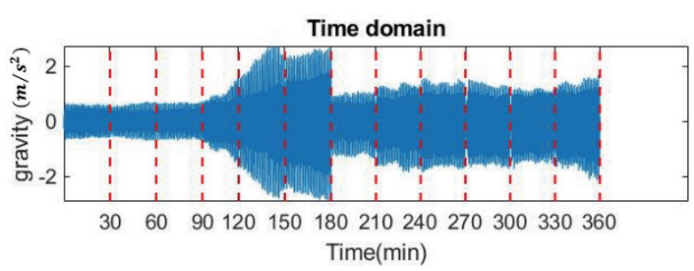

(a)

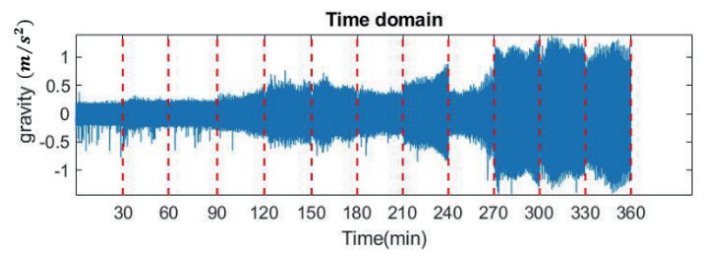

(b)

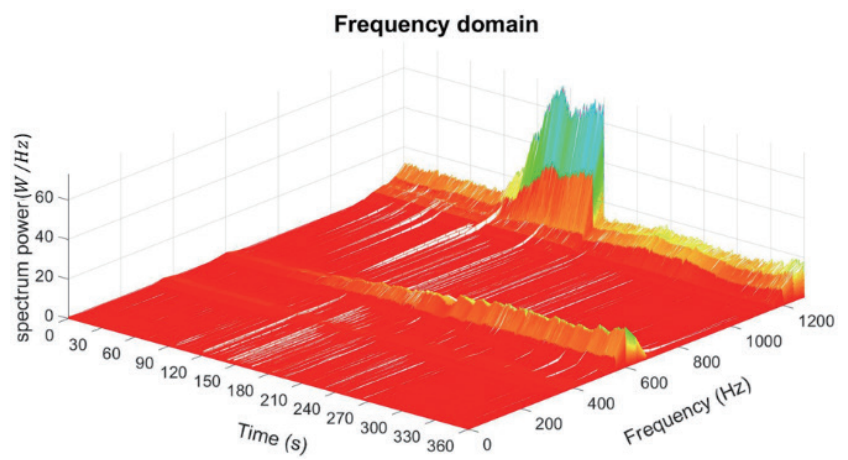

(c)

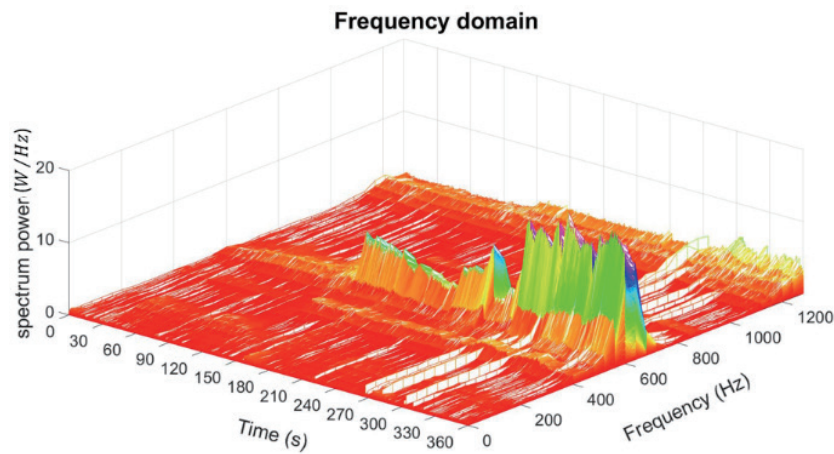

(d)

Fig. 5. (Color online) Vibration spectrum diagrams. (a) Time domain diagram of the accelerometer on the fixture. (b) Time domain diagram of the accelerometer on the spindle. (c) Time-frequency diagram of the fixture. (d) Timefrequency diagram of the spindle guard.

energy appeared in two frequency bands of 500-700 and 1200-1280 Hz, and the strongest energy in the grinding process should be generated on the grinding wheel and the workpiece. In addition, the energy intensity generated by an object closer to the accelerometer will be stronger, so it can be concluded that the $1200-1280 \mathrm{~Hz}$ frequency band, which produced higher energy at the fixture, is the characteristic frequency band corresponding to the workpiece, and the 500$700 \mathrm{~Hz}$ frequency band is the characteristic frequency band corresponding to the grinding wheel.

In this study, the accelerometers were placed under the workpiece jig and at the end of the spindle guard. The vibration signals of the accelerometers during the grinding processes were used to analyze the changes in the grinding characteristics of the grinding wheels. Figure 5(a) 
shows the vibration signals from 0 to 360 min with the accelerometer placed under the fixture. The magnitude of the vibration signals was $\pm 0.72 \mathrm{~m} / \mathrm{s}^{2}$ and relatively consistent for $0-90 \mathrm{~min}$. However, the signals gradually become stronger, with the magnitude increasing from $\pm 0.72 \mathrm{~m} / \mathrm{s}^{2}$ at $90 \mathrm{~min}$ to $\pm 1.85 \mathrm{~m} / \mathrm{s}^{2}$ at $180 \mathrm{~min}$. Between 180 and $360 \mathrm{~min}$, the average magnitude was $\pm 1.26 \mathrm{~m} / \mathrm{s}^{2}$. The increase in the vibration signal magnitude from 90 to $180 \mathrm{~min}$ was caused by the pore packing of the internal pores of the grinding wheel. The decrease in the vibration signal magnitude between 180 and 360 min was caused by the partial removal of the material packed in the internal pores of the grinding wheel. The vibration signals from 180 to 360 min were larger than those from 0 to $90 \mathrm{~min}$ in the grinding process owing to the wear of the grinding wheel.

When the accelerometer was placed on the spindle guard of the grinding wheel, the vibration signal magnitude was $\pm 0.23 \mathrm{~m} / \mathrm{s}^{2}$ and relatively consistent between 0 and $90 \mathrm{~min}$. However, after 90 min of grinding, the vibration signal magnitude gradually increased, reaching $\pm 0.88 \mathrm{~m} / \mathrm{s}^{2}$ after $240 \mathrm{~min}$. This was because the grinding chips began to slowly fill the pores of the grinding wheel. After $240 \mathrm{~min}$, the packing layer fell off, and the vibration signal magnitude decreased from \pm 0.88 to $\pm 0.45 \mathrm{~m} / \mathrm{s}^{2}$. Between 270 and $360 \mathrm{~min}$, the vibration signal magnitude increased to $\pm 1.33 \mathrm{~m} / \mathrm{s}^{2}$ owing to the packing of grinding chips.

\subsection{Relationship between surface roughness and vibration signals at fixture and spindle guard}

From the energy change in the time-frequency diagram, it can be observed that the energy in the main characteristic frequency band of the fixture increased rapidly between 90 and $210 \mathrm{~min}$, so the accelerometer received the vibration signals. The temporal changes in acceleration, $R_{a}$ and $R_{Z}$, are plotted in Fig. 6. $R_{a}$ and $R_{Z}$ significantly increased between 90 and $210 \mathrm{~min}$. After 210 min, the acceleration energy dropped sharply, but the vibration signal was still in a higher energy range than that after $90 \mathrm{~min}$, and $R_{a}$ and $R_{Z}$ were also relatively high, indicating the deterioration of the surface accuracy of the grinding process.

Figure 7 shows the relationship between the spectrum power variation and roughness of grinding machining in the time-frequency diagram. The spectrum power was in the main characteristic frequency band of the spindle guard. The relationships between the energy of the main characteristic frequency band at the grinding wheel, $R_{a}$ and $R_{Z}$, were examined. In the experiment, $R_{a}$ increased earlier than the signal of the spindle guard, and $R_{Z}$ increased with the increase in energy between 90 and $180 \mathrm{~min}$, similarly to the previous experiments, and all spectrum power variation was at a high value. The oscillating spectrum power showed no obvious correlation with the acceleration because the signal energy at the grinding wheel does not correspond to the surface roughness. Consequently, as the acceleration energy increased for the first time, a larger amount of workpiece chip filings became attached to the grinding wheel and a larger amount of the grinding wheel grit was fractured. The subsequent large fluctuations in $R_{a}$ and $R_{Z}$ were caused by self-sharpening phenomena, such as random fracture, adhesion, shedding, and wear of the grinding wheel. 


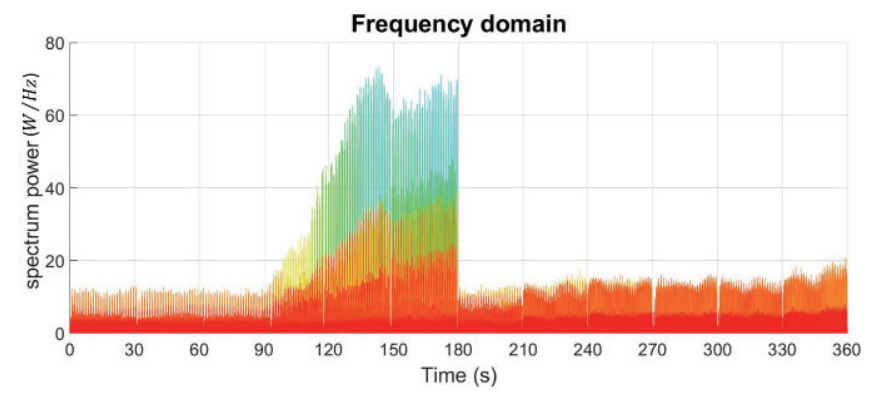

(a)

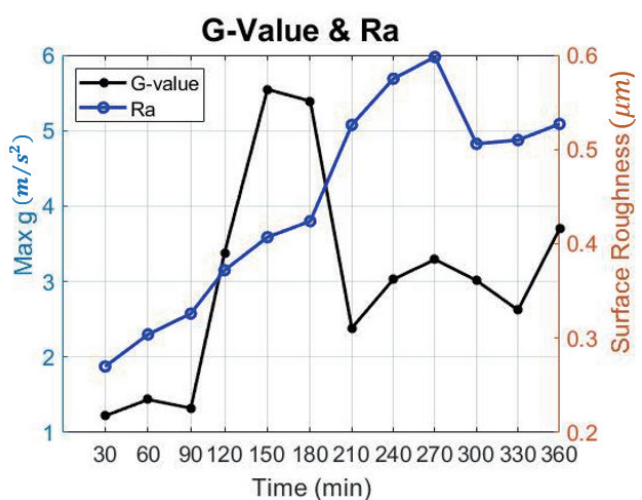

(b)

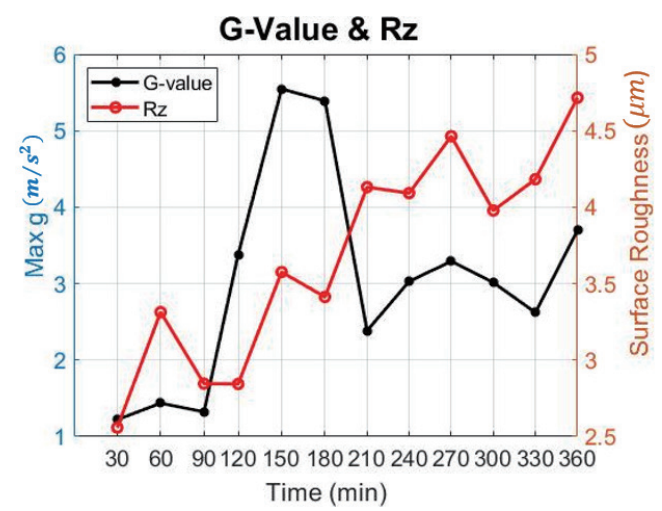

(c)

Fig. 6. (Color online) Vibration signals and temporal changes in $R_{a}$ and $R_{Z}$ of the fixture. (a) Frequency domain of the fixture. (b) Vibration signal and $R_{a}$ of the fixture. (c) Vibration signal and $R_{Z}$ of the fixture.

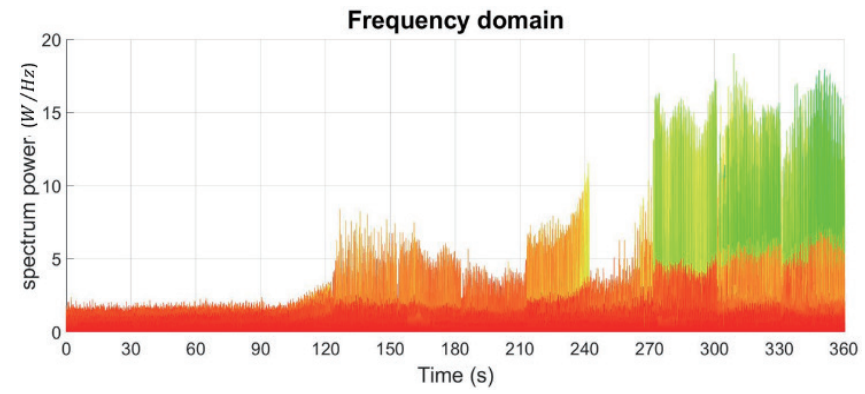

(a)

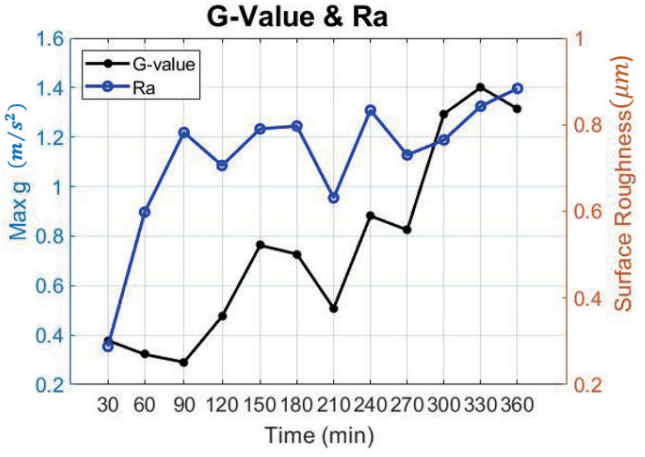

(b)

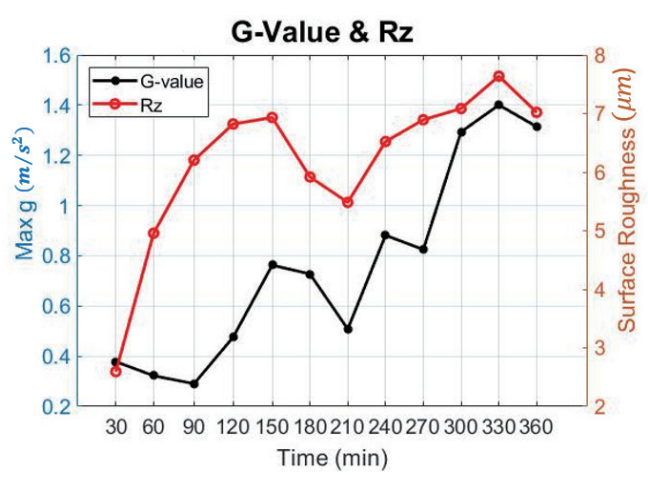

(c)

Fig. 7. (Color online) Vibration signals and temporal changes in $R_{a}$ and $R_{Z}$ of the spindle guard. (a) Frequency domain of the spindle guard. (b) Vibration signal and $R_{a}$ of the spindle guard. (c) Vibration signal and $R_{Z}$ of the spindle guard. 


\subsection{Surface roughness after grinding}

Figure 8 shows the surface roughness and SEM images of the workpiece after grinding. The surface roughness increased with the use time of the grinding wheel. $R_{a}$ increased from 0.270 $\mu \mathrm{m}$ (30 $\mathrm{min})$ to $0.527 \mu \mathrm{m}(360 \mathrm{~min})$ and $R_{Z}$ increased from $2.559 \mu \mathrm{m}(30 \mathrm{~min})$ to $4.716 \mu \mathrm{m}(360$ $\min )$.

The relationship between the amount of vibrations and time was obtained by analyzing the vibration spectrum of the grinding energy of the grinding wheel by wavelet transform, ${ }^{(24)}$ as shown in Fig. 9. From the results, it is found that out of the total energy of all acceleration signals during the grinding process, the grinding energies at 500-700 and $1200-1280 \mathrm{~Hz}$ accounted for 29.88 and $56.45 \%$, respectively.

\subsection{Results of optical microscopy (OM) measurements}

The experimental results indicated that $R_{a}$ and $R_{Z}$ increased when the acceleration energy rose sharply for the first time, and then they oscillated up and down after $90 \mathrm{~min}$. An accelerometer was placed on the spindle guard to measure whether this was related to the change in the topography of the grinding wheel and the results are shown in Fig. 10. From the OM

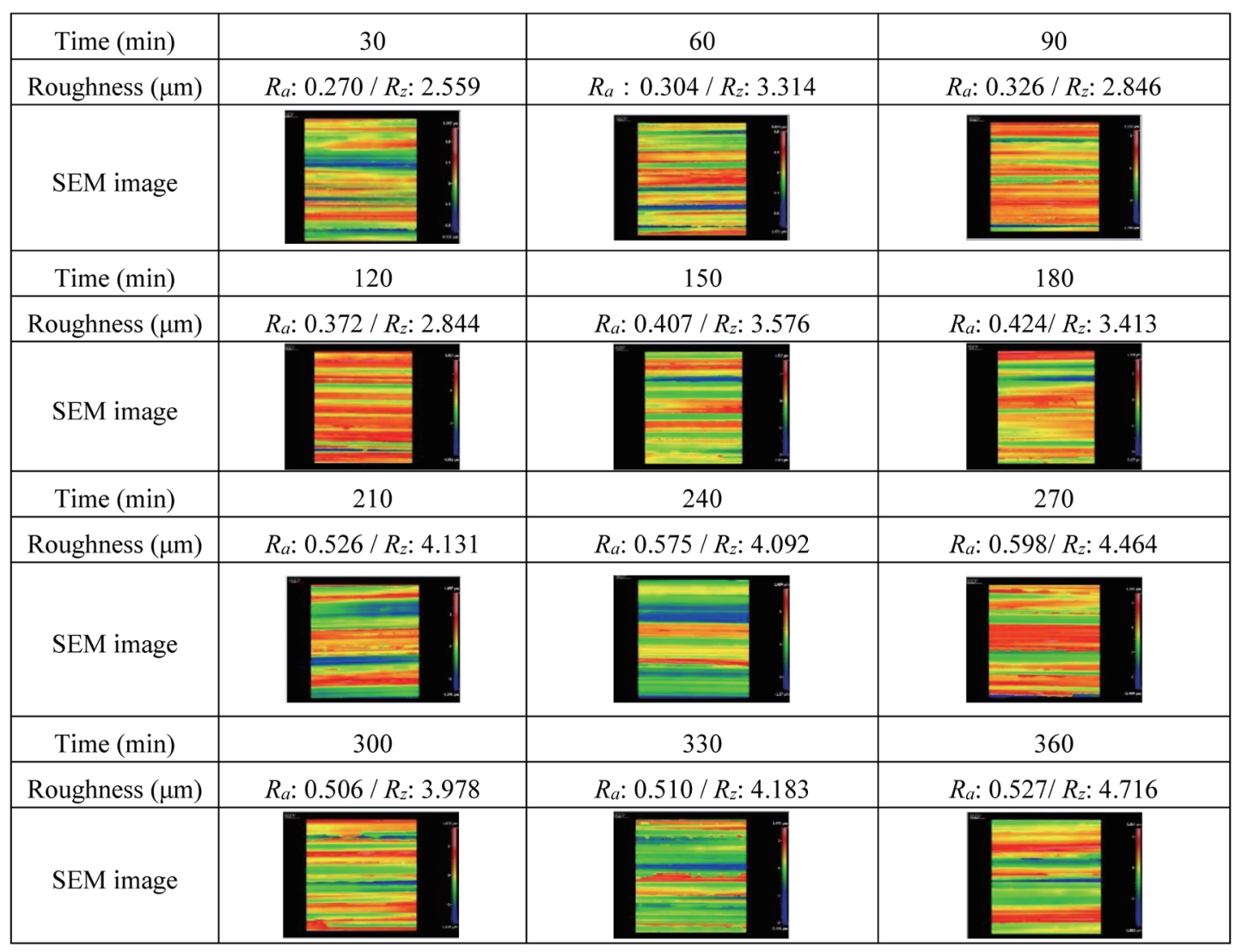

Fig. 8. (Color online) Surface roughness and SEM images of workpiece after grinding. 


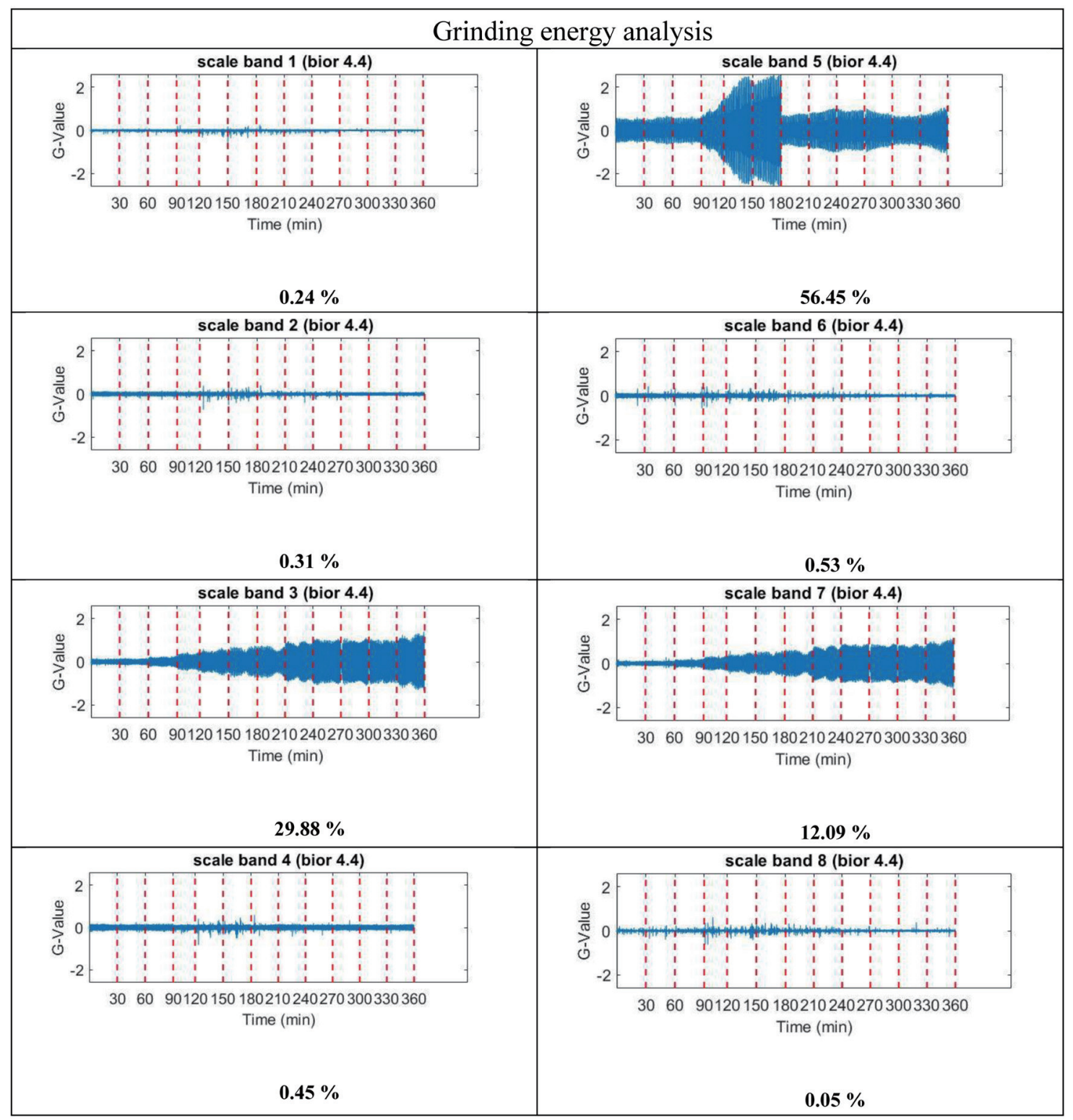

Fig. 9. (Color online) Grinding energy analysis.

images and the changes in the surface accuracy and acceleration signals within $360 \mathrm{~min}$, it is found that from 90 to $120 \mathrm{~min}$, workpiece chips adhered to the gap of the grinding wheel, which caused the surface accuracy to deteriorate and the energy of the acceleration signal to increase. As the energy began to rise again at $270 \mathrm{~min}$, it was observed that the grinding chips of the previous layer peeled off the surface of the grinding wheel along with the self-sharpening phenomena, and a new re-adhesion started to form. This also caused the energy to increase again and the energy of the second surge was much higher than that of the first surge, which means that the self-sharpening of the grinding wheel did not completely return the grinding wheel to its best condition. As a result, grinding chips easily and quickly accumulated, resulting in a sharp increase in the cutting force caused by insufficient grinding capacity. 


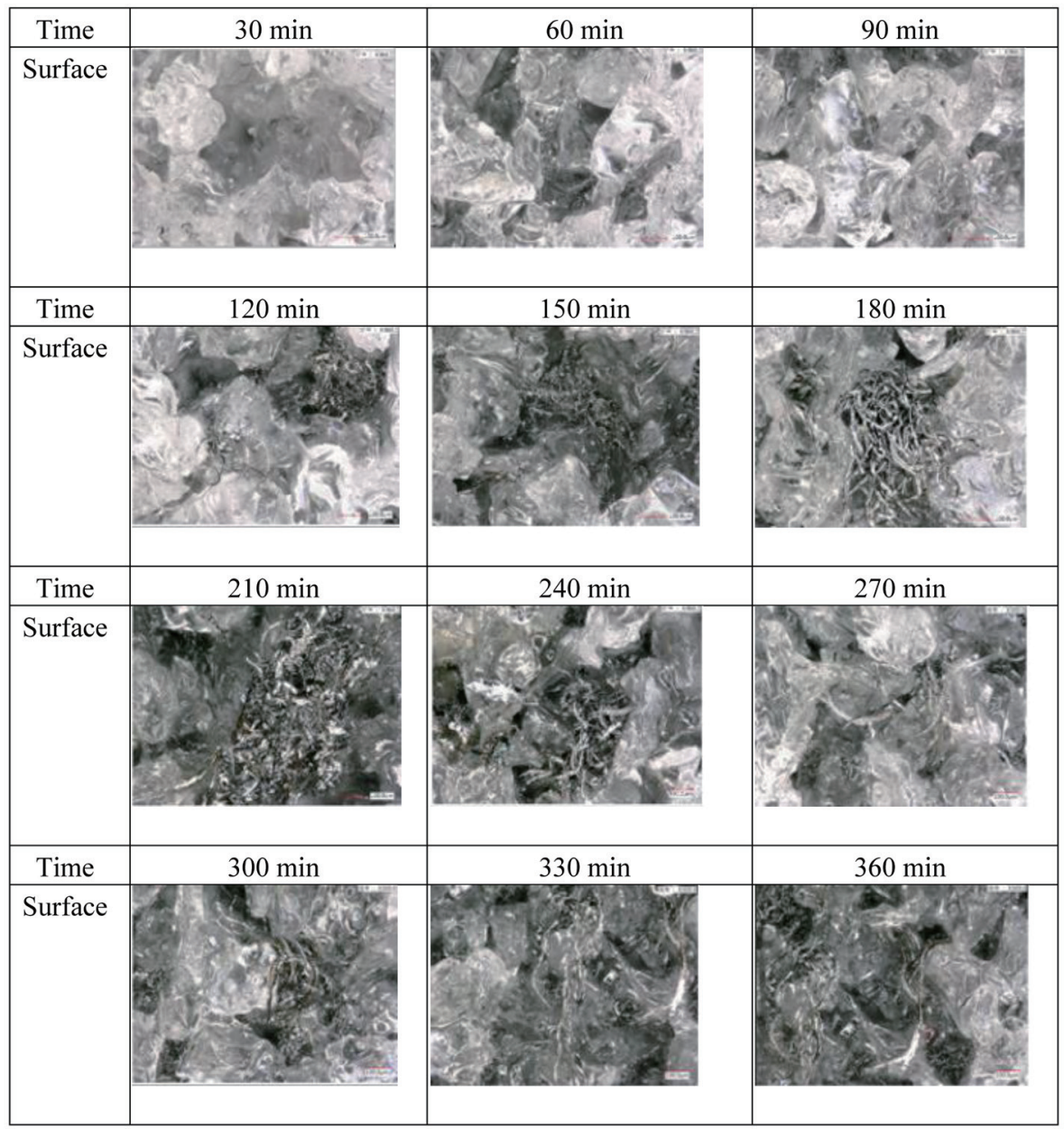

Fig. 10. (Color online) Surface of grinding wheel during grinding.

On the basis of this phenomenon, by applying STFT to the signal and by observing the main frequency band of the grinding wheel, one can clearly observe the beginning and end of the selfsharpening phenomena of the grinding wheel.

\section{Conclusions}

In this study, accelerometer sensors were used to collect the acceleration signals of a grinding machine during grinding, and STFT was utilized to process the signals to find the relationship between the wear of the grinding wheel and the characteristic frequency band during the grinding process. In the experiments, the time-frequency diagram obtained after collecting the accelerometer signals and STFT led to the following conclusions:

1. The frequency bands of the grinding wheel and the workpiece were 500-700 and $1200-1280 \mathrm{~Hz}$, respectively. By comparison between the known frequency band and the time-frequency diagram of the sensing signal at the fixture with $R_{a}$ and $R_{Z}$ it was found that when the spectral energy increased, the surface roughness of the workpiece increased 
significantly, and then even if the self-sharpening was completed, the surface roughness of the workpiece remained high.

2. The signal obtained at the spindle guard of the grinding wheel provided a good explanation for the self-sharpening phenomena, such as the adhesion of grinding chips on the surface of the grinding wheel. The beginning and end of the self-sharpening phenomena could be clearly observed from the signal obtained at the spindle guard, and during the second selfsharpening phenomenon, the energy was much higher than that during the first phenomenon. It is speculated that the self-sharpening phenomena could not perfectly return the grinding wheel to its best condition and that the insufficient grinding ability caused the energy to rise sharply.

\section{Acknowledgments}

The authors gratefully acknowledge the financial support provided to this study by the Ministry of Science and Technology of Taiwan under grants MOST 109-2622-E167-010-CC3, 109-2634-F-009-031, and 110-2222-E-167-001-MY3.

\section{References}

1 J. Kopac and P. Krajnik: J. Mater. Process. Technol. 175 (2006) 278. https://doi.org/10.1016/j. jmatprotec.2005.04.010

2 J. F. G. Oliveria, E. J. Silva, C. Guo, and F. Hashimoto: CIRP Annals. 58 (2009) 663. https://doi.org/10.1016/j. cirp.2009.09.006

3 Z. Shang, C. Xu, G. Xie, J. Yi, and H. Huang: J. Mech. Sci. Technol. 32 (2018) 3283. https://doi.org/10.1007/ s12206-018-0630-x

4 B. C. Kim, J. H. Chung, M. W. Cho, S. J. Ha, and G. S. Yoon: J. Mech. Sci. Technol. 32 (2018) 3345. https://doi. org/10.1007/s12206-018-0637-3

5 S. Bhowmika and R. Naikb: Proc. 2018 ScienceDirect Materials Today: Proc. (ScienceDirect, 2018) 28602864. https://doi.org/10.1016/j.matpr.2018.01.077

6 Y. Zhu, W. Ding, Z. Rao, and Y. Fu: Wear 426 (2019) 1573. https://doi.org/10.1016/j.wear.2018.12.064

7 R. Pavel and A. Srivastava: Int. Adv. Manuf. Technol. 33 (2007) 412. https://doi.org/10.1007/s00170-006-0771$\underline{4}$

8 D. Herman and J. Krzos: J. Mater. Process. Technol. 209 (2009) 5377. https://doi.org/10.1016/j. jmatprotec.2009.03.013

9 G. Q. Yin, Y. D. Gong, Y. W. Li, and J. Cheng: J. Mech. Sci. Technol. 32 (2018) 3817. https://doi.org/10.1007/ s12206-018-0734-3

10 C. Wu, B. Lia, J. Yanga, and S. Y. Liangb: J. Ceram. Process. Res. 17 (2016) 223.

11 A. Srivastava, A. Awale, M. Vashista, M. Zaheer, and K. Yusufzai: J. Mech. Sci. Technol. 34 (2020) 2145. https://doi.org/10.1007/s12206-020-0435-6

12 C. W. Dai, W. F. Dinga, Y. J. Zhua, J. H. Xua, and H. W. Yub: Precis. Eng. 52 (2018) 192. https://doi. org/10.1016/j.precisioneng.2017.12.005

13 W. B. Rowe, L. Yan, I Inasaki, and S. Malkin: CIRP Ann. 43 (1994) 521. https://doi.org/10.1016/S0007$\underline{\text { 8506(07)60498-3 }}$

14 T. Maksoud, M. Atia, and M. Koura: Mach. Sci. Technol. 7 (2003) 361. https://doi.org/10.1081/MST-120025284

15 Z. S. Yang and Z. H. Yu: Int. J. Adv. Manuf. Technol. 62 (2012) 107. https://doi.org/10.1007/s00170-011-3797-1

16 A. Arriandiaga, E. Portillo, J. A. Sánchez, I. Cabanes, and I. Pombo: Sensors 14 (2014) 8756. https://doi. org $/ 10.3390 / \mathrm{s} 140508756$

17 A. Arriandiaga, E. Portillo, J. A. Sánchez, and I. Cabanes: Int. Conf. Engineering Applications of Neural Networks, Rhodes, Greece (2015) 24-34. https://doi.org/10.1007/978-3-319-23983-5_3

18 A. Arriandiaga, E. Portillo, J. Sánchez, I. Cabanes, and A. Zubizarreta: Neural. Comput. Appl. 28 (2017) 1293. https://doi.org/10.1007/s00521-016-2568-1 
19 X. Han and T. Wu: Int. J. Adv. Manuf. Technol. 67 (2013) 1997. https://doi.org/10.1007/s00170-012-4626-X

20 W. N. Lopes, F. L. Ferreira, F. A. Alexandre, D. M. S. Ribeiro, P. O. C. Junior, P. R. Aguiar, and E. C. Bianchi: Inst. Eng. Technol. 11 (2017) 631. https://doi.org/10.1049/iet-smt.2016.0317

21 Z. Wang, P. Willett, P. R. Aguiar, and J. Webster: Int. J. Machine Tools Manuf. 41 (2001) 283. https://doi. org/10.1016/S0890-6955(00)00057-2

22 C. H. R. Martins and P. R. Aguiar: IEEE Trans. Instrum. Meas. 63 (2014) 667. https://doi.org/10.1109/ TIM.2013.2281576

23 J. B. Allen and L. R. Rabiner: Proc. IEEE 65 (1977) 1558-1564. https://doi.org/10.1109/PROC.1977.10770

24 P. S. Addison: The Illustrated Wavelet Transform Handbook (CRC Press, 2017) 2nd ed., Chap. 4.

\section{About the Authors}

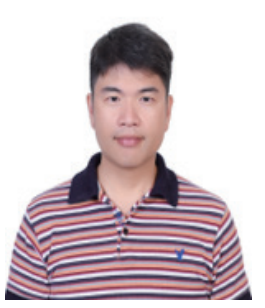

Kun-Ying Li was born in Chiayi, Taiwan, in 1979. From 2007 to 2020, he was an engineer with the Intelligent Machinery Technology Center, Industrial Technology Research Institute from 2007 to 2020. He received his Ph.D. degree from National Chin-Yi University of Technology, Taiwan, in 2020. He has been an assistant professor since 2020. His research interests include thermal errors of machine tools, design for precision machinery, and reliability engineering and applications. He holds 14 patents in machine tools. (likunying@ncut.edu.tw)

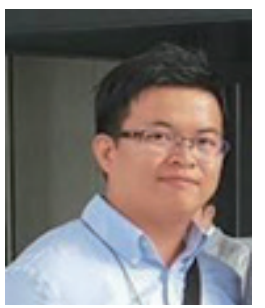

Yue-Feng Lin received his B.S. degree from National Cheng-Kung University, Taiwan, in 2008 and his M.S. and Ph.D. degrees from National Cheng-Kung University in 2009 and 2016, respectively. From 2017 to 2018, he was a postdoctoral researcher at National Chung Hsing University, Taiwan. Since 2018, he has been an assistant professor at National Chin-Yi University of Technology, Taiwan. His research interests include machining and finishing of difficult-to-cut materials. (yflin@ncut.edu.tw)

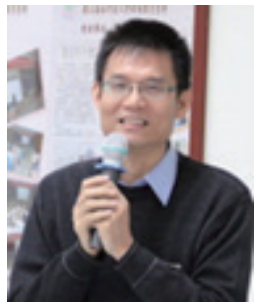

Ming-Yi Tsai was born in Yunlin, Taiwan, in 1968. He received his B.S. degree from the Department of Mechanical Engineering, National Taiwan University of Science and Technology and his M.S. degree from the Department of Mechanical Engineering, National Chung Hsing University, Taiwan, in 1998. He received his Ph.D. degree from National Taiwan University, Taiwan. He is now a professor at the Department of Mechanical Engineering, National Chin-Yi University of Technology. His research interests include grinding and polishing of difficult-to-cut materials. (mytsai@ncut.edu.tw)

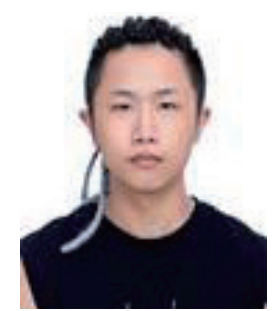

I-Cheng Chiu was born in Taoyuan, Taiwan, in 1997. He received his B.S. degree in Mechanical Engineering from National Chin-Yi University of Technology, Taiwan, in 2020. His research interests include digital signal processing of machine chatter, abrasive development, and polishing process application technology. (Learn20200106@gmail.com) 
Jyun-Yan Chen was born in Taipei, Taiwan, in 1989. He received his B.S. and M.S. degrees in mechanical engineering from National Chin-Yi University of Technology, Taiwan, in 2011 and 2015, respectively. From 2017 to 2018, he had an internship with the quality control department of RE-DAI Precision Tools Co., Ltd. (jack1baycomtw@gmail.com) 